\title{
Correction to: The Involvement of Cell Adhesion Molecules, Tight Junctions, and Gap Junctions in Human Placentation
}

\author{
Enoch Appiah Adu-Gyamfi ${ }^{1,2}$ - Armin Czika ${ }^{2}$ - Philip Narteh Gorleku ${ }^{3} \cdot$ Amin Ullah $^{2} \cdot$ Zulqarnain Panhwar $^{2}$. \\ Ling-Ling Ruan ${ }^{2} \cdot$ Yu-Bin Ding ${ }^{1,2} \cdot$ Ying-Xiong Wang ${ }^{1,2}$
}

Published online: 3 December 2020

(C) Society for Reproductive Investigation 2020

\section{Correction to: Reprod. Sci.} https://orcid.org/10.1007/s43032-020-00364-7

This article was updated to correct a spacing problem in the caption of Figure 2 and to delete the word "preeclamptic" in the first sentence of the second paragraph on page 8 .

Publisher's Note Springer Nature remains neutral with regard to jurisdictional claims in published maps and institutional affiliations.

The online version of the original article can be found at https://doi.org/ $10.1007 / \mathrm{s} 43032-020-00364-7$

Enoch Appiah Adu-Gyamfi

orkamanyame@gmail.com

$\triangle \quad$ Yu-Bin Ding

dingyb@cqmu.edu.cn

$\triangle$ Ying-Xiong Wang

1600347366@qq.com

1 Department of Reproductive Sciences, School of Basic Medicine,

Chongqing Medical University, Chongqing 400016, People's

Republic of China

2 Joint International Research Laboratory of Reproduction \& Development, Chongqing Medical University, Box 197, No. 1

Yixueyuan Rd, Chongqing 400016, People's Republic of China

3 Department of Medical Imaging, School of Medical Sciences, University of Cape Coast, Cape Coast, Republic of Ghana 